\section{Fasciola hepatica as an uncommon cause of cholangitis}

A 45-year-old man with fever, jaundice, and right upper quadrant abdominal pain was referred to our Clinic for emergency decompression of the biliary tract owing to acute cholangitis. Laboratory data showed elevated liver enzymes: alkaline phosphatase, 490IU/L; gamma-glutamyl transpeptidase, $1685 \mathrm{IU} / \mathrm{L}$; alanine aminotransferase, $260 \mathrm{IU} / \mathrm{L}$; aspartate aminotransferase, $195 \mathrm{IU} / \mathrm{L}$; total bilirubin level, $360 \mathrm{IU} / \mathrm{L}$ (reference range: $0-20.5 \mathrm{IU} / \mathrm{L}$ ); leukocytosis, $13.5 \times 10^{9} / \mathrm{L}$.

Magnetic resonance cholangiopancreatography (MRCP) was done and showed a possible filling defect in the common bile duct (CBD) with moderate dilation of the intrahepatic bile ducts, predominantly in the left liver lobe ( $\boldsymbol{~ F i g . 1 a ) . ~}$ Endoscopic retrograde cholangiopancreatography (ERCP) was performed and revealed a dilated CBD $(11 \mathrm{~mm})$ with an oval filling defect in the mid part of the CBD ( $\bullet$ Fig. $\mathbf{1 b}$ ) suspected to be a stone. During balloon extraction after endoscopic sphincterotomy, an unexpected parasite suggestive of Fasciola hepatica was forced through the bile duct orifice ( $\odot$ Fig. 1 c) and into the duodenal lumen. After the procedure, the patient was given single dose of triclabendazole $(500 \mathrm{mg})$ and on follow-up 4 weeks later, he was asymptomatic with all liver enzymes having returned to normal. On transabdominal ultrasound, the bile duct appeared of normal caliber.
Biliary tree obstruction and acute cholangitis are usually the consequence of choledocholithiasis, malignant or benign stricture with parasites being a rare cause [1]. The life cycle of Fasciola hepatica is complex and humans are accidental hosts $[1,2]$.

Biliary parasitosis may lead to a series of complications such as obstructive jaundice, pyogenic cholangitis, acute pancreatitis, intrahepatic stones, liver abscesses, acute or chronic cholecystitis, and even cholangiocarcinoma and hepatocellular carcinoma [1-3]. Imaging techniques such as ultrasound, computed tomography, and MRCP are usually non-specific [4]. Only the serology and identification of ova in the stool or duodenal aspirates are specific, but not routinely done in clinical practice [1].

ERCP is able to demonstrate directly the presence of parasites and, in conjunction with anti-helminthic drugs, it is the treatment of choice to remove parasites [5].

Endoscopy_UCTN_Code_CCL_1AZ_2AI

Competing interests: None

\section{Daniel Popa', Ivan Jovanovic ${ }^{2,3}$, Dejan Radenkovic ${ }^{3,4}$}

Gastroenterology Department, Polisano Clinic, Sibiu, Romania
${ }^{2}$ Clinic for Gastroenterology and Hepatology, Clinical Center of Serbia, Belgrade, Serbia

${ }^{3}$ Medical School, University of Belgrade, Belgrade, Serbia

${ }^{4}$ First Surgical Clinic, Clinical Center of Serbia, Belgrade, Serbia

\section{References}

1 Rana SS, Bhasin D, Nanda $M$ et al. Parasitic infestations of the biliary tract. Curr Gastroenterol Rep 2007; 9: 156-164

2 Kaya M, Beştaş R, Cetin S. Clinical presentation and management of Fasciola hepatica infection: Single-center experience. World J Gastroenterol 2011; 17: 4899-4904

3 Gulsen MT, Savas MC, Koruk M et al. Fascioliasis: A report of five cases presenting with common bile duct obstruction. Neth J Med 2006; 64: 17-19

4 Dusak A, Onur MR, Cicek M et al. Radiological imaging features of Fasciola hepatica infection - a pictorial review. J Clin Imaging Sci 2012; $2: 2-3$

5 Ezzat RF, Karboli TA, Kasnazani KA et al. Endoscopic management of biliary fascioliasis: a case report. J Med Case Rep 2010; 4: 83

\section{Bibliography}

DOI http://dx.doi.org/

10.1055/s-0034-1390719

Endoscopy 2014; 46: E600

(c) Georg Thieme Verlag KG

Stuttgart · New York

ISSN 0013-726X

\section{Corresponding author}

\section{Ivan Jovanovic, MD, PhD}

Clinic for Gastroenterology and Hepatology

Clinical Center of Serbia

Koste Todorovic 2

11000 Belgrade

Serbia

Fax: +381-11-3615587

ivangastro@beotel.rs
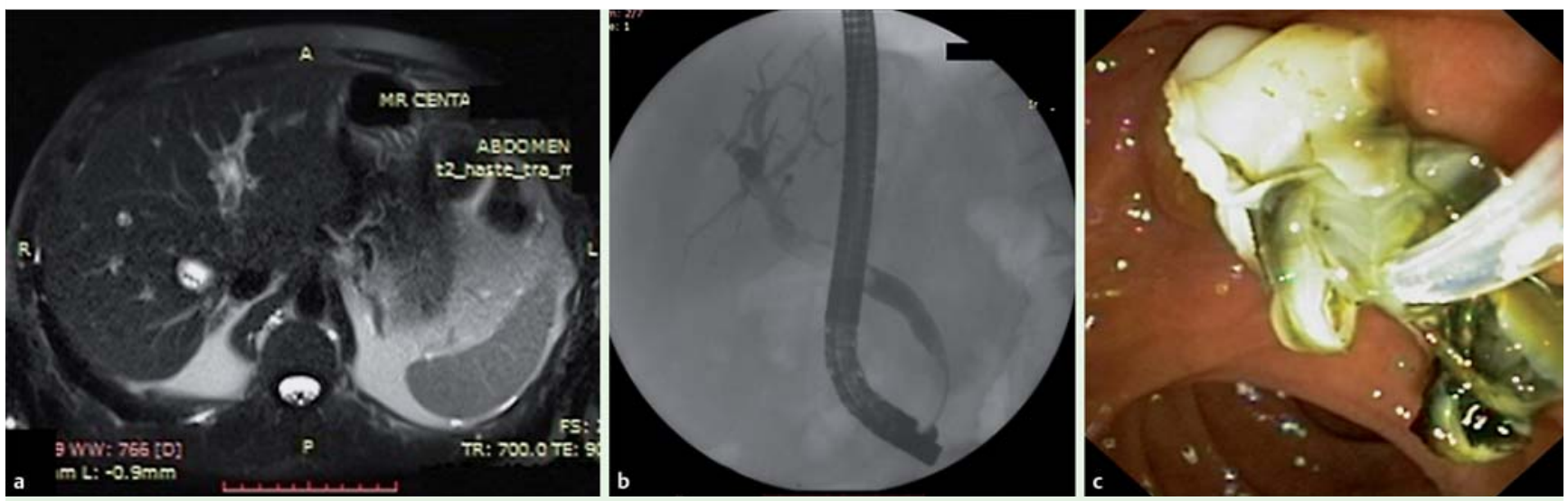

Fig. 1 A 45-year-old man with fever, jaundice, and right upper quadrant abdominal pain was admitted for emergency decompression of the biliary tract owing to acute cholangitis. a Transverse T2-weighted magnetic resonance image (MRI) shows dilation of the common bile duct (11 mm) and moderate dilation of the intrahepatic bile ducts (more prominent in the left lobe). $\mathbf{b}$ Endoscopic retrograde cholangiopancreatography (ERCP) showing a filling defect in the mid part of the common bile duct (CBD). c Fasciola coming out of the CBD after sphincterotomy and balloon catheter extraction. 